\title{
Corrigendum
}

\section{Corrigendum to "Temperature Effect on Yield and Yield Components of Different Rice Cultivars in Flowering Stage"}

\author{
Seyede Roghie Ghadirnezhad Shiade $\mathbb{I D}^{1}$ and Allahyar Fallah ${ }^{2}$ \\ ${ }^{1}$ Department of Agronomy, Ghaemshahr Branch, Islamic Azad University, Ghaemshahr, Iran \\ ${ }^{2}$ Rice Research Institute of Amol, Amol, Mazandaran 46191-91951, Iran \\ Correspondence should be addressed to Seyede Roghie Ghadirnezhad Shiade; mina_620062@yahoo.com \\ Received 15 September 2020; Accepted 15 September 2020; Published 17 October 2020 \\ Copyright (C) 2020 Seyede Roghie Ghadirnezhad Shiade and Allahyar Fallah. This is an open access article distributed under the \\ Creative Commons Attribution License, which permits unrestricted use, distribution, and reproduction in any medium, provided \\ the original work is properly cited.
}

In the article titled "Temperature Effect on Yield and Yield Components of Different Rice Cultivars in Flowering Stage" [1], the authors' full names were not published. The author list is being updated to include the full names above.

\section{References}

[1] S. R. G. Shiade and A. Fallah, "Temperature effect on yield and yield components of different rice cultivars in flowering stage," International Journal of Agronomy, vol. 2014, Article ID 846707, 4 pages, 2014. 